\title{
Depressive symptoms in first episode psychosis: a one-year follow-up study
}

\author{
Nasrettin Sönmez ${ }^{1,2^{*}}$, Kristin Lie Romm¹, Ole A Andreasssen², Ingrid Melle ${ }^{2}$ and Jan Ivar Røssberg ${ }^{1,2}$
}

\begin{abstract}
Background: Depressive symptoms are common in patients with first episode psychosis (FEP) and have serious consequences for them. The main aims of this study were to examine the course of depression in FEP patients and explore whether any patient characteristics at baseline predicts depressive symptoms after one year.

Method: A total of 198 FEP patients with schizophrenia spectrum disorders were assessed for depressive symptoms with Calgary Depression Scale for Schizophrenia (CDSS) at baseline and 127 were followed for one year. A CDSS score [greater than or equal to] 6 was used as a cut-off score for depression.

Results: Approximately $50 \%$ of the patients were depressed (CDSS[greater than or equal to]6) at baseline. At follow-up approximately 35\% had depression. The course of depressive symptoms varied, $26 \%$ was depressed at both baseline and follow-up, 9\% became depressed during the follow-up, 22\% remitted from depression during the 12 months and $43 \%$ was neither depressed at baseline nor at follow-up. Poor childhood social functioning, long duration of untreated psychosis (DUP) and depressive symptoms at baseline predicted depression at 12 months follow-up.

Conclusion: Depressive symptoms are frequent in the first year after onset of psychosis. Patients with poor social functioning in childhood, long DUP and depressive symptoms at baseline are more prone to have depressive symptoms after one year. These patients should be identified and proper treatment provided.
\end{abstract}

\section{Background}

Depressive symptoms are common in patients with a first episode psychosis (FEP) with a reported prevalence from $17 \%$ to $83 \%$ in the different studies [1-4]. This wide variation in prevalence may be due to heterogeneity in the study population, variation of assessment tools and the study's definition of depression. Depressive symptoms occur in different phases of the psychosis, including prodromal [5,6], acute [7] and post-psychotic phases [8,9]. They have thus been regarded as intrinsic to schizophrenia psychopathology, similar to positive, negative, and disorganized symptom clusters [10].

There are only few studies examining the course and development of depressive symptoms in patients with a FEP. This is important as there is an increased risk of

\footnotetext{
*Correspondence: nasrettin.sonmez@medisin.uio.no

'Oslo University Hospital, (TIPS Sor Ost) Centre of Competence for Early Intervention in Psychosis, Fridtjof Nansens vei 12, Oslo 0369, Norway ${ }^{2} \mathrm{KG}$ Jebsen Centre for Psychosis Research, Division of Mental Health and Addiction and Oslo University Hospital, Institute of Clinical Medicine, University of Oslo, Pb 85, Oslo 0319, Norway
}

suicide during the early phases of psychotic illness $[11,12]$. Furthermore, knowledge about the course of depressive symptoms may facilitate earlier identification of patients who are prone to develop a severe course. In line with this, Cotton and coworkers [13] emphasized the need for prospective studies mapping the trajectory of depressive symptoms in psychotic disorders to provide a critical step towards developing a clear understanding of the phenomenology of depressive pathology in the early phases of psychotic disorders.

To our knowledge only five studies have explored the course of depression in FEP over time; and two of these were acute treatment outcome studies which only explored the course of depressive symptoms from admission to discharge (between 39 and 56 days) [3,14]. Riedel and colleagues [14] found that depressed first-episode schizophrenia patients scored significantly higher on all PANSS subscales (PANSS total, PANSS positive and PANSS negative) both at admission and discharge. However, Bottlender and coworkers [3] found that depressive symptoms in the acute psychotic phase was a positive

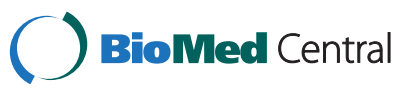

(c) 2013 Sönmez et al.; licensee BioMed Central Ltd. This is an Open Access article distributed under the terms of the Creative Commons Attribution License (http://creativecommons.org/licenses/by/2.0), which permits unrestricted use, distribution, and reproduction in any medium, provided the original work is properly cited. 
prognostic indicator for patients concerning negative symptoms.

Oosthuizen and coworkers [15] assessed changes in depressive symptoms over a two-years period. They found that depressive symptoms experienced during an acute psychotic episode were different from those experienced in the post-psychotic period. Acute depressive symptoms were related to psychotic symptoms, and these symptoms improved when the psychotic symptoms resolved in response to antipsychotic treatment. Depressive symptoms observed in the post-psychotic period were referred to as 'persistent depressive symptoms', because they were not responsive to antipsychotic therapy alone.

Cotton and colleagues [13] aimed to determine if there were differences in the clinical and functional characteristics of FEP patients with and without depressive symptoms during an18 months early intervention treatment program [16]. The group with depressive symptoms at baseline was less hospitalized and had less substance abuse during treatment. At discharge patients in this group were also more likely to be depressed and had better insight concerning their illness. The depressed group of patients was also significantly more likely to have a past diagnosis of personality disorder, suicide attempts, a shorter duration of treatment, ongoing substance abuse, lower GAF mean score and were less likely to be working.

Upthegrove and colleagues [17] examined prospectively the course of depression in prodromal, acute, and 12 months follow-up period of psychosis. Including a total of 82 patients, they found that prodromal depression was significantly linked with the development of depression in the acute and follow-up phases, and acute depression was also significantly related with the development of later depression. Severity of depression was not significantly correlated with the severity of positive and negative symptoms in the acute or follow-up phases.

As seen from this review there is a need for a wider and more elaborated examination of the association between the course of depressive symptoms, patient characteristics and outcome.

In the present study we examined the course of depressive symptoms during a 12 month follow-up period.

We aimed to answer the following questions:

1. How many FEP patients are scored as depressed measured by CDSS (CDSS $\geq 6$ ) at baseline and at 12 months follow-up?

2. Is it possible to identify subgroups of patients with different profiles of depressive symptoms during a one-year follow-up period, and can these subgroups be differentiated on demographic characteristics such as DUP, premorbid functioning (PAS) and clinical characteristics (PANSS scores)?

3. To what extent are there any differences in suicidality, between these groups?

4. To what extent do patient characteristics at baseline predict 12 months CDSS scores?

\section{Method}

\section{Subjects}

A total of 198 patients with a first episode psychosis (FEP) were included at baseline from the ongoing Thematically Organized Psychosis Research (TOP) study at the Oslo University Hospital and University of Oslo, Norway. Of these, a total of 127 patients were followed for one year. Romm and colleagues have previously reported the baseline characteristics of 119 of the 198 patients included in the present study [4]. The present study is a further exploration of depressive symptoms in a 12 months follow-up period.

These samples were included from March 2004 to February 2010. The inclusion criteria were (1) age 18 to 65 years and a first episode non-affective psychosis according to Diagnostic and Structural Manual of Mental Disorders, fourth edition (DSM-IV) [18]. Exclusion criteria were a history of organic brain disorder, a significant comorbid medical condition, or an IQ below 70 .

Inclusion was based on the time from the first onset of positive psychotic symptoms (the first week with a PANSS score of 4 or more on Positive Scale Items 1, 3, 5,6 or General Scale item 9) to the start of first admission to the study [19]. Patients with previous treatment with antipsychotic medication in adequate dosage for more than 12 weeks were not considered as FEP patients.

The study is approved by the Regional Committee for Medical Research Ethics and the Norwegian Data Inspectorate. A written informed consent was obtained from all of the participants.

\section{Clinical assessment and instruments}

Diagnosis was set by the Structural Clinical Interview for DSM-IV axis I disorders (SCID I) [18]. Current symptom severity was assessed on the Positive and Negative Syndrome Scale (PANSS) [20] and characterized by five subscales; positive, negative, excitative, depressive, and cognitive [21]. Depression was assessed using the Calgary Depression Scale for Schizophrenia (CDSS) [22]. CDSS has been shown to be reliable and valid and it measures depression separate from negative or extrapyramidal symptoms $[23,24]$. In a systematic review of instruments measuring depressive symptoms, the CDSS outperformed other depression instruments in terms of reliability and validity in patients with schizophrenia [25]. The cut-off score for depression varies between 
three and nine in the different studies [15,17,26-28]. We chose to use a cut-off score of equal and/or above six, in line with some of the previous studies [28-30]. Suicidality was measured with the CDSS-suicide item. Premorbid functioning was assessed with the Premorbid Adjustment Scale (PAS) [31]. The premorbid phase is defined as the time from birth until six months before onset of psychosis. PAS measures social and academic functioning in 4 time periods; childhood, early adolescence, late adolescence, and adult life. We decided to focus on social and academic functioning in childhood and early adolescence only. It may be difficult to discern between premorbid and psychotic symptoms in late adolescence when the first psychotic episode usually occur. General level of symptoms and functioning was assessed with the Global Assessment of Functioning scale (GAF), split version [32,33]. Problem drinking was screened by the Alcohol Use Disorders Identification Test (AUDIT) [34], and use of illegal drugs was assessed with Drug Use Disorders Identification Test (DUDIT) [35]. DUP was measured following the criteria described by Larsen et al. [36]. At 12-month follow-up the participants were re-assessed with the following instruments: GAF, PANSS, CDSS, AUDIT and DUDIT.

\section{Reliability}

Clinical interviews were carried out by trained psychologists and psychiatrists. The interviewers were all enrolled in the general training and reliability program in the TOP study. For DSM-IV diagnostics, mean overall kappa with training videos was 0.77 (95\% confidence interval [CI]: 0.60-0.94). Interrater reliability, measured by the interclass correlation coefficient (1.1), was for the PANSS positive subscale 0.82 (95\% CI: 0.66-0.94), for the PANSS negative subscale 0.76 (95\% CI: 0.58-093), the PANSS general subscale 0.73 ( $95 \%$ CI: 0.54-0.90), the GAF symptom scale 0.86 (95\% CI: 0.77-0.92), and the GAF functioning scale 0.85 (95\% CI: 0.76-0.92).

\section{Analysis}

Statistical analysis was done by using SPSS for Windows (version 16.0). Descriptive statistics was performed on the whole sample to obtain the independent variables' frequencies, means and standard deviations. To identify different subgroups of patients with different trajectories of depressive symptoms, we used a cut-off score above or equal six on the CDSS. Based on the CDSS scores we wanted to identify patients who were depressed in the whole follow-up period, patients who were depressed at baseline, but recovered during the follow-up period, patients who became depressed during the follow-up period, and finally patients who never were scored as depressed during the follow-up period. One-Way ANOVA was performed in order to compare the means of the follow-up subgroups. Bivariate correlations were used to study the correlation of each independent variable with CDSS total scores at both baseline and 12-month follow-up.

DUP required transformation to its natural logarithm $(\operatorname{Ln}[\mathrm{DUP}+1])$.

Hierarchical multiple linear regression was used to assess the ability of baseline variables to predict depression (CDSS total score) at 12-month follow-up. The predictors were selected based on theoretical considerations: gender differences, neurocognitive developmental issues (premorbid functioning in childhood), and basic psychopathological/psychotic symptoms that may have association with the development of depressive symptoms in FEP. To estimate how much of the variance each of the patient variables explained, we used a blockwise multiple hierarchic regression analysis. Gender was entered in the first block, because this variable must be considered as the most basic one. PAS childhood social and academic were entered in the second block as a measure of early social and academic functioning. The duration of psychosis was entered in the third block. Finally, we entered the five different PANSS subscales which we considered as the most important variables in predicting depressive symptoms at 12 months follow-up. By entering the PANSS subscale scores in the fourth block, we controlled for the amount of variance explained by the variables in the three first blocks.

\section{Results}

Table 1 displays the baseline characteristics of the patients. The mean age at baseline was 27.98 years, the range was from 17 to 56, and 127 (64\%) of the sample were men. A total of 152 (77\%) patients were European (at least one parent), 34 were married/cohabited (17\%), 118 (77\%) had high school and 74 (37\%) were working or studying. A total of $60(30 \%)$ patients lived alone and 57 (29\%) were living with their parents. The diagnostic distribution was as follows: schizophrenia 102 ( 51.5\%), schizophreniform disorder 17 ( 8.5\%), schizoaffective disorder 10 ( $5.0 \%)$, brief psychotic disorder 8 ( $4.0 \%)$, delusional disorder 9 ( $4.5 \%)$, psychotic disorder not otherwise specified 52 ( $26.5 \%)$.

A total of 96 (48.5\%) patients had a score of CDSS $\geq 6$ at baseline. At follow-up $44(34.6 \%)$ patients had a score above or equal six. The associations between these patients' demographic and clinical characteristics and their CDSS total score at baseline and at 12 months follow-up are also presented in Table 1.

CDSS at baseline correlated significantly with GAF S, PANSS excitative, PAS childhood social and academic, PAS early adolescence social and academic, DUP, Insight (PANSS g12) and AUDIT. Among the demographic variables there was only gender that correlated significantly with CDSS-total at baseline (female most depressed). At 
Table 1 Mean and SD of patients' demographic and clinical baseline characteristics and their correlations with CDSS total scores at baseline $(n=198)$ and 12-month follow-up $(n=127)$

\begin{tabular}{|c|c|c|c|}
\hline & Mean (SD) & $\begin{array}{l}\text { Correlation With CDSS total } \\
\text { score at baseline (Pearson) }\end{array}$ & $\begin{array}{l}\text { Correlation with CDSS total score } \\
\text { at12-month follow-up (Pearson) }\end{array}$ \\
\hline Age & $27.98(8.70)$ & 0.01 & 0.10 \\
\hline Gender (M) & $N=127(64 \%)$ & $0.18^{*}$ & 0.13 \\
\hline Education (year) & $12.71(2.93)$ & -0.02 & -0.13 \\
\hline GAF symptom & $41.12(11.38)$ & $-0.29 * *$ & $-0.26^{* *}$ \\
\hline GAF function & $44.14(12.65)$ & -0.11 & $-0.22^{*}$ \\
\hline PANSS positive & $12.95(4.49)$ & 0.07 & 0.06 \\
\hline PANSS negative & $20.13(7.72)$ & 0.11 & $0.18^{*}$ \\
\hline PANSS excitative & $8.07(2.84)$ & $0.21 *$ & -0.04 \\
\hline PANSS depressive & $12.15(3.61)$ & $0.58^{* *}$ & $0.37^{* *}$ \\
\hline PANSS cognitive & $5.38(2.07)$ & -0.004 & 0.06 \\
\hline PANSS-total score & $63.38(15.00)$ & $0.27^{* *}$ & $0.23 *$ \\
\hline PAS childhood social & $2.51(3.05)$ & $0.26^{* *}$ & $0.32 * *$ \\
\hline PAS childhood academic & $3.45(2.43)$ & $0.26^{* *}$ & $0.26^{* *}$ \\
\hline PAS early adolescence social & $2.69(2.88)$ & $0.21 * *$ & $0.22 *$ \\
\hline PAS early adolesc. academic & $4.26(2.75)$ & $0.24 *$ & 0.17 \\
\hline DUPIn & $1.63(0.80)$ & $0.23 * *$ & $0.30^{* *}$ \\
\hline Insight (PANSS G12) & $2.76(1.36)$ & $-0.18^{*}$ & -0.11 \\
\hline AUDIT & $7.76(7.70)$ & $0.17^{*}$ & 0.09 \\
\hline DUDIT & $6.36(9.58)$ & 0.10 & 0.03 \\
\hline Anti-depressive medication day dosis & $37.50(35.75)$ & 0.05 & 0.03 \\
\hline Anti-psychotic medication, day dosis & $97.17(155.88)$ & -0.05 & -0.07 \\
\hline CDSS total baseline & $6.23(4.44)$ & -二———————-—— & $0.48^{* *}$ \\
\hline
\end{tabular}

*Correlation is significant at the 0.05 level (2-tailed).

**Correlation is significant at the 0.01 level (2-tailed).

PANSS Positive and negative syndrome scale.

GAF Global assessment of functioning.

PAS Premorbid adjustment scale.

DUP Duration of untreated psychosis.

AUDIT Alcohol use disorders identification test.

DUDIT Drug use disorders identification test.

CDSS Calgary depression scale for schizophrenia.

12 months follow-up CDSS correlated significantly with baseline GAF S and GAF F, PANSS negative and depressive component, PAS childhood social and academic, and PAS early adolescence social, and DUP.

The course of depressive symptoms during the 12 months period followed four different pathways: Group 1) thirty-three patients (26\%) were depressed at both baseline and follow-up (G1; Persistent depression), Group 2) eleven patients (9\%) had no depressive symptoms at baseline, but developed depressive symptoms during the 12-months follow-up (G2; Depression follow-up), Group 3) twenty-eight patients (22\%) had depressive symptoms at baseline and remitted during the 12 months follow-up (G3; Depression baseline), Group 4) fifty five patients (43\%) had no depressive symptoms neither at baseline nor at follow-up (G4; No depression) (Table 2).
Table 2 shows the differences between the four groups at baseline. As displayed, the Persistent depression group (G1) scored significantly different compared to the group no depression. (G4) concerning GAF S, PAS childhood social, academic and PAS early adolescence social. Regarding CDSS suicide score at baseline, G1 had significantly higher score than both G2 and G4, and G3 had significantly higher suicidality score than G2.

Table 3 displays the differences between the four groups at 12 months follow-up. The most notable difference was, between G1 and G4. G1 had higher levels of global symptoms (GAF S), poorer functioning (GAF F) and more negative and excitative symptoms (PANSS components). Regarding CDSS suicide score, G1 had significantly higher score at follow-up than all the other three subgroups. 
Table 2 Comparison of the 4 subgroups regarding baseline variables

\begin{tabular}{|c|c|c|c|c|c|}
\hline & $\begin{array}{l}\text { G1: Persistent } \\
\text { depression } \\
\mathrm{N}=33\end{array}$ & $\begin{array}{l}\text { G2: depression } \\
\text { follow-up } \\
\mathrm{N}=11\end{array}$ & $\begin{array}{l}\text { G3: depression } \\
\text { baseline } \\
\text { N }=\mathbf{2 8}\end{array}$ & $\mathrm{N}=55$ & $\begin{array}{l}\text { Significant } \\
\text { difference(s) } \\
\text { between; }\end{array}$ \\
\hline \multirow[t]{2}{*}{ Gender (M) } & $18 / 55 \%$ & $8 / 73 \%$ & $15 / 54 \%$ & $41 / 75 \%$ & \\
\hline & Mean (SD) & Mean (SD) & Mean (SD) & Mean (SD) & \\
\hline Age & $28.3(8.71)$ & $28.0(5.90)$ & $23.9(5.00)$ & $27.2(7.81)$ & \\
\hline GAF symptom & $37.58(8.58)$ & $39.36(8.61)$ & $38.93(8.58)$ & $45.31(14.87)$ & G1 and G4 (.034) \\
\hline GAF function & $40.24(12.37)$ & $43.00(11.81)$ & $42.39(11.93)$ & $47.53(14.34)$ & \\
\hline PANSS Positive & $13.52(4.24)$ & $13.45(5.26)$ & $13.61(4.68)$ & $12.76(4.89)$ & \\
\hline PANSS Negative & $21.83(8.06)$ & $21.36(7.75)$ & $21.93(7.89)$ & $18.78(6.84)$ & \\
\hline PANSS Excitative & $7.88(1.90)$ & $7.00(2.10)$ & $8.66(2.94)$ & $7.55(2.41)$ & \\
\hline \multirow[t]{3}{*}{ PANSS Depressive } & $14.79(2.10)$ & $13.55(4.53)$ & $12.96(2.59)$ & $9.89(3.09)$ & G1 and G4 (.000) \\
\hline & & & & & G2 and G4 (.003) \\
\hline & & & & & G3 and G4 (.000) \\
\hline PANSS Cognitive & $5.67(2.16)$ & $5.36(2.16)$ & $5.39(1.93)$ & $5.38(1.87)$ & \\
\hline \multirow[t]{2}{*}{ PANSS-total } & $68.50(12.22)$ & $65.91(11.90)$ & $67.78(14.90)$ & $58.56(13.34)$ & G1 and G4 (.013) \\
\hline & & & & & G3 and G4 (.038) \\
\hline AUDIT & $8.87(8.63)$ & $4.70(7.45)$ & $9.21(5.63)$ & $6.46(7.53)$ & \\
\hline DUDIT & $7.16(11.18)$ & $2.40(4.60)$ & $5.21(8.59)$ & $7.27(10.03)$ & \\
\hline \multirow[t]{2}{*}{ PAS Childhood social } & $4.09(3.75)$ & $2.36(2.54)$ & $1.96(2.60)$ & $1.69(2.24)$ & G1 and G4 (.003) \\
\hline & & & & & G1 and G3 (.038) \\
\hline PAS Childhood academic & $4.29(2.44)$ & $4.45(3.21)$ & $3.54(2.76)$ & $2.55(1.92)$ & G1 and G4 (.017) \\
\hline PAS Early adolescence social & $4.06(3.55)$ & $2.27(2.57)$ & $2.71(2.68)$ & $2.05(2.44)$ & G1 and G4 (.020) \\
\hline PAS Early adolesc. academic & $4.71(2.83)$ & $4.82(3.06)$ & $4.25(3.04)$ & $3.22(2.30)$ & \\
\hline DUPin & $4.17(1.76)$ & $3.86(1.78)$ & $3.44(1.85)$ & $3.35(1.68)$ & \\
\hline \multirow[t]{3}{*}{ CDSS-suicide } & $.91(.678)$ & $.18(.405)$ & $.75(.645)$ & $.11(.315)$ & G1 and G4 (.000) \\
\hline & & & & & G1 and G2 (.002) \\
\hline & & & & & G2 and G3 (.035) \\
\hline
\end{tabular}

PANSS Positive and negative syndrome scale.

GAF Global Assessment of Functioning.

PAS Premorbid adjustment scale.

DUP Duration of untreated psychosis.

AUDIT Alcohol use disorders identification test.

DUDIT Drug use disorders identification test.

CDSS Calgary depression scale for schizophrenia.

A blockwise multiple regression analysis was conducted in order to detect possible variables at baseline that might predict depressive symptoms at 12 months follow-up. The included variables explained a total of $25 \%$ of the variance in the level of depression as measured by the CDSS. PAS childhood social, DUP, and PANSS depressive symptoms explained a significant proportion of the variance (Table 4 ).

\section{Discussion}

The present study showed that depressive symptoms are frequent during the first year of treatment in FEP. Approximately half of the patients had depression at start of treatment while more than one third were depressed at one-year follow-up. In line with other studies $[8,13,14,17]$ the depressive symptoms decreased during the follow-up period.

Furthermore, we detected four different trajectories of depressive symptoms during a 12 months follow-up. The four groups differed significantly as it comes to patient characteristics and clinical variables. The most notably difference was between G1 (persistent depression) and G4 (no depression). G1 scored significantly higher on global symptoms in addition to premorbid adjustments (PAS childhood social and academic score, and PAS early adolescence social score) at baseline. At 12 months follow-up the differences between the two groups were even more pronounced. Most notably the group with persistent depression scored poorer on GAF F, and the PANSS negative symptom scale. 
Table 3 Comparison of the 4 subgroups regarding 12 months follow up variables

\begin{tabular}{|c|c|c|c|c|c|}
\hline & $\begin{array}{l}\text { G1: Persistent depression } \\
\qquad N=33\end{array}$ & $\begin{array}{l}\text { G2: Depression follow-up } \\
\qquad N=11\end{array}$ & $\begin{array}{l}\text { G3: Depression baseline } \\
\qquad \mathrm{N}=\mathbf{2 8}\end{array}$ & $\begin{array}{l}\text { G4: No depression } \\
\qquad \mathrm{N}=55\end{array}$ & $\begin{array}{l}\text { Significant } \\
\text { difference(s) } \\
\text { between; }\end{array}$ \\
\hline \multirow[t]{2}{*}{ Gender (M) } & $18 / 54 \%$ & $8 / 73 \%$ & $15 / 54 \%$ & $41 / 75 \%$ & \\
\hline & Mean (SD) & Mean (SD) & Mean (SD) & Mean (SD) & \\
\hline Age & $28.33(8.71)$ & $28.00(5.90)$ & $23.86(5.00)$ & $27.20(7.81)$ & \\
\hline \multirow[t]{4}{*}{ GAF symptom } & $40.21(10.45)$ & $40.45(10.37)$ & $58.52(15.66)$ & $54.36(17.10)$ & G1 and G4 (.001) \\
\hline & & & & & G1 and G3 (.000) \\
\hline & & & & & G2 and G4 (.049) \\
\hline & & & & & $\mathrm{G} 2$ and $\mathrm{G} 3(.011)$ \\
\hline \multirow[t]{2}{*}{ GAF function } & $42.42(11.22)$ & $43.82(13.35)$ & 57.48 (15.58) & $56.60(16.07)$ & G1 and G4 (.000) \\
\hline & & & & & G1 and G3 (.002) \\
\hline PANSS Positive & $12.65(4.74)$ & $13.64(6.03)$ & $9.24(3.97)$ & $10.42(5.57)$ & \\
\hline PANSS Negative & $21.24(7.12)$ & $19.73(7.39)$ & $16.71(6.31)$ & $16.57(5.54)$ & G1 and G4 (.013) \\
\hline PANSS Excitative & $7.76(2.56)$ & $7.18(2.44)$ & $6.54(1.67)$ & $6.46(2.02)$ & G1 and G4 (.064) \\
\hline \multirow[t]{4}{*}{ PANSS Depressive } & $13.70(3.11)$ & $13.64(3.38)$ & $8.29(2.21)$ & $8.74(3.15)$ & G1 and G4 (.000) \\
\hline & & & & & G1 and G3 (.000) \\
\hline & & & & & G2 and G4 (.000) \\
\hline & & & & & $\mathrm{G} 2$ and G3 (.000) \\
\hline PANSS Cognitive & $5.61(2.51)$ & $5.82(1.54)$ & $4.93(2.28)$ & $4.93(2.03)$ & \\
\hline \multirow[t]{4}{*}{ PANSS-total } & $65.82(13.29)$ & $64.36(12.21)$ & $49.11(12.08)$ & $50.67(13.76)$ & G1 and G4 (.000) \\
\hline & & & & & G1 and G3 (.000) \\
\hline & & & & & G2 and G4 (.023) \\
\hline & & & & & $\mathrm{G} 2$ and G3 (.017) \\
\hline AUDIT & $9.29(7.40)$ & $3.40(4.97)$ & $4.88(4.65)$ & $6.35(7.31)$ & \\
\hline DUDIT & $5.55(8.04)$ & $.20(.63)$ & $4.04(5.60)$ & $4.58(8.65)$ & \\
\hline \multirow[t]{3}{*}{ CDSS-suicide } & $.79(.740)$ & $.36(.505)$ & $.04(.189)$ & $.02(.135)$ & G1 and G4 (.000) \\
\hline & & & & & G1 and G2 (.045) \\
\hline & & & & & G1 and G3 (.000) \\
\hline
\end{tabular}

PANSS Positive and negative syndrome scale.

GAF Global assessment of functioning.

PAS Premorbid adjustment scale.

DUP Duration of untreated psychosis.

AUDIT Alcohol use disorders identification test.

DUDIT Drug use disorders identification test.

CDSS Calgary depression scale for schizophrenia.

As it comes to suicidality the group with persistent depression (G1) was, as expected, more suicidal than the other groups. However, there were also significant differences in level of suicidal thoughts at follow-up between this group (G1) and the group with depression follow-up (G2), in spite of the fact that they had equal levels of depression. As shown in table three the PANSS depressive component was almost the same between the two groups.

Birchwood and colleagues [9] emphasized the need for making clear distinctions between three core but not mutually exclusive pathways to depression in schizophrenia; a) depression that is intrinsic to the psychosis diathesis, b) depression as a reaction to the psychotic episode and c) depression as a product of disturbed developmental pathways resulting from developmental trauma and the childhood antecedents of psychosis. Based on the current findings, one could speculate that the group with persistent depression (G1) corresponds to the pathway that explain depressive symptoms in psychosis as intrinsic to the psychosis diathesis [9]. This type of depression is seen as an essential aspect of the schizophrenic process being an artefact of negative symptoms and Parkinsonism in a limited subgroup of patients whom these symptoms are particularly severe [37]. Accordingly, G1 had the highest PANSS-negative score and significantly higher score than the G4's PANSS-negative score. 
Table 4 Blockwise multiple regression analysis of the relationship between baseline characteristics and CDSS total score

\begin{tabular}{|c|c|c|c|c|c|c|}
\hline & B & Standard error & Significance & Lower bound & Upper bound & Adjusted R square \\
\hline Gender & .703 & .660 & .289 & -.603 & .289 & .009 \\
\hline PAS child. social & .319 & .118 & $.008^{*}$ & .085 & .552 & \\
\hline PAS child. academic & .044 & .142 & .755 & -.237 & .325 & .111 \\
\hline DUP & .558 & .181 & $.003^{*}$ & .198 & .917 & .171 \\
\hline PANSS positive & -.057 & .071 & .420 & -.198 & .083 & \\
\hline PANSS negative & .039 & .46 & .397 & -.053 & .132 & \\
\hline PANSS excitative & -.248 & .130 & .060 & -.506 & .010 & \\
\hline PANSS depressive & .348 & .093 & $.000^{* *}$ & .165 & .532 & \\
\hline PANSS cognitive & .046 & .177 & .797 & -.305 & .396 & .251 \\
\hline
\end{tabular}

Explained variance for final model: $R^{2}=.305, F=5.608, P<.05$.

* Significant at the $\mathrm{P}<.05$ level.

** Significant at the $\mathrm{P}<.001$ level.

PANSS Positive and negative syndrome scale.

PAS Premorbid adjustment scale.

DUP Duration of untreated psychosis.

CDSS Calgary depression scale for schizophrenia.

Upthegrove and colleagues emphasizes how some patients with a psychotic disorder may be more vulnerable to persistent depression. According to them, there may be a depression that begins in adolescence, presents itself during the prodromal phase and re-emerges at future times as a response to varied stressors [17]. This is to some extent in line with the current findings in G1. This group seems to be more vulnerable not only to depression, but shows more global and overall psychological symptoms and has the lowest premorbid function (childhood social, academic and early adolescent social). Vulnerability to depression for this group may be partly due to the severity of these symptoms. That this group did not significantly differ from G2 and G3 in positive and negative symptoms may indicate that depression in FEP is not only intrinsic to psychotic symptoms, but also a reaction to the more acute constraint of general and global psychological symptoms which develop during the psychotic episode.

To our knowledge, the present study is the first to examine if baseline socio-demographic and clinical characteristics predict depressive symptoms 12 months after start of therapy. Patients with poor premorbid social functioning in childhood, long duration of untreated psychosis and depressive symptoms at baseline have more depressive symptoms at 12 months follow-up. The group with persistent depression (G1) had most global and psychotic symptoms, as well as the highest suicide scores at both baseline and follow-up. It is of great importance to recognize such a group of FEP patients as early as possible, in order to provide a better prognosis and to prevent depressive symptoms and suicidality. Riedel and colleagues [14] examined predictors of depression in the acute phases of psychosis in patients treated with risperidone and haloperidol. However, they did not, as in the present study, examine patient characteristics that could predict depressive symptoms after the acute phases of the psychoses. Upthegrove and co-authors [17] found that depressive symptoms in the acute phase of psychosis predicted depressive symptoms at 12 months follow-up. This is in line with the findings in our study. In addition, we show that a long DUP and poor premorbid social functioning in childhood predicts depressive symptoms at 12 months follow-up. Premorbid functioning has previously been associated with long term treatment outcome [38-42] However, this is the first study that have showed that premorbid functioning is important for the development of depressive symptoms in FEP patients.

\section{Limitations}

\section{Limitation of the study concern drop-out}

The results in the present study could be influenced by the relatively high drop-out rate $(n=71,36 \%)$ from baseline to 12 months follow-up. This represents loss of valuable information and may weaken the validity of the findings. The patients who dropped out were most often untraceable and did not respond to letters or phone calls. Unfortunately, no additional information about reasons for dropping out from the study was registered. However, there were no significant differences at baseline between those patients who dropped-out and the group who were interviewed at 12 months follow-up as it comes to gender distribution, age, symptoms and diagnostic distribution.

It could be argued that the results of the present study are influenced by the overlap between negative symptoms and depressive symptoms. However, the present study revealed no significant correlation between the PANSS negative component scores and the CDSS total 
scores at baseline and only a low but significant correlation (0.18) between these two measures at 12 months follow up. Even if we can not rule out an overlap between these negative and depressive symptoms, it would probably have no major consequences for the results.

This study has not measured any qualitative aspects by being depressed. The group of patients who were continously depressed could have different reasons for being depressed at respectively baseline and 12 months follow up. Factors like not being able to attend school or work, might cause depressive symptoms just after the onset of psychotic symptoms. Furthermore, negative voices putting the patients down, internal and external stigma might cause depressive symptoms. These aspects and how they are related to the course of depressive symptoms in patients with psychosis should be explored in future studies. In the present study, we examined whether some of the items comprising CDSS were scored differently at baseline and 12 months follow up for the continously depressed patients. No significant differences were found.

\section{Conclusion}

Depressive symptoms are frequent in FEP patients, both at baseline and 12 months follow-up. Patient characteristics such as premorbid social functioning, duration of untreated psychosis and PANSS score of depression at baseline predict depressive symptoms at 12 months follow-up. Patients with different depressive symptoms trajectories differed on both baseline socio-demographic and clinical characteristics. These findings may be useful for improving identification and management of depressive symptoms in FEP patients.

\section{Study design}

1) Prevalence of depressive symptoms in two different measurement times; A baseline versus B 1-year.

2) Exploration of the course of depressive symptoms during the 1-year follow-up.

\footnotetext{
Abbreviations

FEP: First episode psychosis; PANSS: Positive and negative syndrome scale: GAF F: Global assessment of functioning, function scale; GAF S: Global assessment of functioning, symptom scale; CDSS: Calgary depression scale for schizophrenia; DUP: Duration of untreated psychosis; PAS: Premorbid adjustment scale; TOP: Thematically organized psychosis research; DSM: Diagnostic and structural manual of mental disorders; AUDIT: Alcohol use disorders identification test; DUDIT: Drug use disorders identification test; ANOVA: Analysis of variance.
}

\section{Competing interest}

This study was supported by ExtraStiftelsen Helse og Rehabilitering. The founding source had no further role in the study design, the collection, analysis and interpretation of data, the writing of the report or the decision to submit the paper for publication.

All authors declare that they have no conflict of interest.

\section{Authors' contributions}

NS: Data analysis, drafting and revising the manuscript; KLR: , Data analysis, conception of the study and revising the manuscript; OAA: conception of the study, collecting data, and revising the manuscript; IM: conception of the study and collecting data, revising the manuscript; JIR: conception of the study and collecting data, analysis, drafting and revising the manuscript. All authors read and approved the final manuscript.

\section{Acknowledgments}

Many thanks to all the patients who joined this study and to the persons who contributed in the collection of the data.

Received: 18 January 2013 Accepted: 16 March 2013 Published: 5 April 2013

\section{References}

1. Sim K, Mahendran R, Siris SG, Heckers S, Chong SA: Subjective quality of life in first episode schizophrenia spectrum disorders with comorbid depression. Psychiatry Res 2004, 129:141-147.

2. Addington D, Addington J, Patten S: Depression in people with firstepisode schizophrenia. Br J Psychiatry Suppl 1998, 172:90-92.

3. Bottlender R, Strauss A, Moller HJ: Prevalence and background factors of depression in first admitted schizophrenic patients. Acta Psychiatr Scand 2000, 101:153-160

4. Romm KL, Rossberg Jl, Berg AO, Barrett EA, Faerden A, Agartz I, et al: Depression and depressive symptoms in first episode psychosis. J Nerv Ment Dis 2010, 198:67-71.

5. Salokangas RK, McGlashan TH: Early detection and intervention of psychosis. A review. Nord J Psychiatry 2008, 62:92-105.

6. Hafner H, Maurer K, Trendler G, An Der Heiden W, Schmidt M: The early course of schizophrenia and depression*. Eur Arch Psychiatry Clin Neurosci 2005, 255:167-173.

7. Levy ST, McGlashan TH, Carpenter WT Jr: Integration and sealing-over as recovery styles from acute psychosis. J Nerv Ment Dis 1975, 161:307-312

8. Knights A, Hirsch SR: "Revealed" Depression and drug treatment for schizophrenia. Arch Gen Psychiatry 1981, 38:806-811.

9. Birchwood M, labal Z, Upthegrove R: Psychological pathways to depression in schizophrenia: studies in acute psychosis, post psychotic depression and auditory hallucinations. Eur Arch Psychiatry Clin Neurosci 2005, 255:202-212

10. Bartels SJ, Drake RE: Depressive symptoms in schizophrenia: comprehensive differential diagnosis. Compr Psychiatry 1988, 29:467-483.

11. Nordentoft M, Mortensen PB, Pedersen CB: Absolute risk of suicide after first hospital contact in mental disorder. Arch Gen Psychiatry 2011, 68:1058-1064

12. Melle I, Larsen TK, Haahr U, Friis S, Johannesen JO, Opjordsmoen S, et al: Prevention of negative symptom psychopathologies in first-episode schizophrenia: two-year effects of reducing the duration of untreated psychosis. Arch Gen Psychiatry 2008, 65:634-640.

13. Cotton SM, Lambert M, Schimmelmann BG, Mackinnon A, Gleeson JF, Berk $M$, et al: Depressive symptoms in first episode schizophrenia spectrum disorder. Schizophr Res 2012, 134:20-26.

14. Riedel M, Mayr A, Seemuller F, Maier W, Klingberg S, Heuser I, et al: Depressive symptoms and their association with acute treatment outcome in first-episode schizophrenia patients: comparing treatment with risperidone and haloperidol. World J Biol Psychiatry 2012, 13:30-38.

15. Oosthuizen P, Emsley R, Niehaus D, Koen L, Chiliza B: The relationships between depression and remission in first-episode psychosis. World Psychiatry 2006, 5:172-176.

16. McGorry PD, Edwards J, Mihalopoulos C, Harrigan SM, Jackson HJ: EPPIC: an evolving system of early detection and optimal management. Schizophr Bull 1996, 22(2):305-326.

17. Upthegrove R, Birchwood M, Ross K, Brunett K, McCollum R, Jones L: The evolution of depression and suicidality in first episode psychosis. Acta Psychiatr Scand 2010, 122:211-218.

18. American Psychiatric Association: Diagnostic and statistical manual of mental disorders (4 $4^{\text {th }}$ ed., text rev.). Washington, DC:; 2000

19. Johannessen JO, Larsen TK, Joa I, Melle I, Friis S, Opjordsmoen S, et al: Pathways to care for first-episode psychosis in an early detection healthcare sector: part of the Scandinavian TIPS study. Br J Psychiatry Supp/ 2005, 48:s24-s28.

20. Kay SR, Fiszbein A, Opler LA: The positive and negative syndrome scale (PANSS) for schizophrenia. Schizophr Bull 1987, 13:261-276. 
21. Bentsen $H$, Munkvold OG, Notland $T H$, Boye B, Bjorge $H$, Lersbryggen $A B$ et al: The interrater reliability of the positive and negative syndrome scale (PANSS. In Int J Methods Psychiatr Res 1996, 3:227-235.

22. Addington $D$, Addington J, Schissel B: A depression rating scale for schizophrenics. Schizophr Res 1990, 3:247-251.

23. Addington D, Addington J, Maticka-Tyndale E, Joyce J: Reliability and validity of a depression rating scale for schizophrenics. Schizophr Res 1992, 6(3):201-208

24. Addington D, Addington J, Maticka-Tyndale E: Specificity of the calgary depression scale for schizophrenics. Schizophr Res 1994, 11(3):239-244.

25. Lako IM, Bruggeman R, Knegtering H, Wiersma D, Schoevers RA, Slooff CJ, et al: A systematic review of instruments to measure depressive symptoms in patients with schizophrenia. J Affect Disord 2012, 140(1):38-47.

26. Rabany L, Weiser M, Werbeloff N, Levkovitz Y: Assessment of negative symptoms and depression in schizophrenia: revision of the SANS and how it relates to the PANSS and CDSS. Schizophr Res 2011, 126(1-3):226-230.

27. Lako IM, Taxis K, Bruggeman R, Knegtering $H$, Burger $H$, Wiersma D, et al: The course of depressive symptoms and prescribing patterns of antidepressants in schizophrenia in a one-year follow-up study. Eur Psychiatry 2012, 27(4):240-244.

28. Maggini C, Raballo A: Exploring depression in schizophrenia. Eur Psychiatry 2006, 21:227-232.

29. Martin-Reyes M, Mendoza R, Dominguez M, Caballero A, Bravo TM, Diaz T, et al: Depressive symptoms evaluated by the calgary depression scale for schizophrenia (CDSS): genetic vulnerability and sex effects. Psychiatry Res 2011, 189(1):55-61.

30. Schennach-Wolff R, Obermeier M, Seemuller F, Jager M, Messer T, Laux G, et al: Evaluating depressive symptoms and their impact on outcome in schizophrenia applying the calgary depression scale. Acta Psychiatr Scand 2011, 123(3):228-238.

31. Cannon-Spoor HE, Potkin SG, Wyatt RJ: Measurement of premorbid adjustment in chronic schizophrenia. Schizophr Bull 1982, 8:470-484

32. Jones SH, Thornicroft G, Coffey M, Dunn G: A brief mental health outcome scale-reliability and validity of the global assessment of functioning (GAF). Br J Psychiatry 1995, 166:654-659.

33. Pedersen G, Hagtvet KA, Karterud S: Generalizability studies of the global assessment of functioning-split version. Compr Psychiatry 2007, 48:88-94.

34. Saunders JB, Aasland OG, Babor TF, de la Fuente JR, Grant M: Development of the alcohol Use disorders identification test (AUDIT): WHO collaborative project on early detection of persons with harmful alcohol consumption-II. Addiction 1993, 88:791-804.

35. Berman AH, Bergman H, Palmstierna T, Schlyter F: Evaluation of the drug Use disorders identification test (DUDIT) in criminal justice and detoxification settings and in a swedish population sample. Eur Addict Res 2005, 11:22-31.

36. Larsen TK, Johannessen JO, Opjordsmoen S: First-episode schizophrenia with long duration of untreated psychosis. Pathways to care. $\mathrm{Br} J$ Psychiatry Suppl 1998, 172:45-52.

37. Hirsch SR, Jolley AG, Barnes TR, Liddle PF, Curson DA, Patel A, et al: Dysphoric and depressive symptoms in chronic schizophrenia. Schizophr Res 1989, 2:259-264.

38. White C, Stirling J, Hopkins R, Morris J, Montague L, Tantam D, et al: Predictors of 10-year outcome of first-episode psychosis. Psychol Med 2009, 39:1447-1456.

39. Kay SR, Lindenmayer JP: Outcome predictors in acute schizophrenia. Prospective significance of background and clinical dimensions. J Nerv Ment Dis 1987, 175:152-160.

40. Addington J, Addington D: Patterns of premorbid functioning in first episode psychosis: relationship to 2-year outcome. Acta Psychiatr Scand 2005, 112:40-46

41. Rabinowitz J, De SG, Harvey PD, Davidson M: Relationship between premorbid functioning and symptom severity as assessed at first episode of psychosis. Am J Psychiatry 2002, 159:2021-2026.

42. Larsen TK, Friis S, Haahr U, Johannessen JO, Melle I, Opjordsmoen S, et al: Premorbid adjustment in first-episode non-affective psychosis: distinct patterns of pre-onset course. Br J Psychiatry 2004, 185:108-115.

doi:10.1186/1471-244X-13-106

Cite this article as: Sönmez et al:: Depressive symptoms in first episode psychosis: a one-year follow-up study. BMC Psychiatry 2013 13:106.

\section{Submit your next manuscript to BioMed Central and take full advantage of:}

- Convenient online submission

- Thorough peer review

- No space constraints or color figure charges

- Immediate publication on acceptance

- Inclusion in PubMed, CAS, Scopus and Google Scholar

- Research which is freely available for redistribution 